Tropical Agricultural Research \& Extension 21 (3 \& 4): 2018

\title{
MORPHOLOGICAL DIVERSITY OF SIXTEEN SRI LANKAN TRADITIONAL RICE AC- CESSIONS EVALUATED UNDER GREENHOUSE CONDITIONS
}

\author{
Prabhashini RHGB*, Ranawake AL and Senanayake SGJN \\ Department of Agricultural Biology, Faculty of Agriculture, University of Ruhuna, Mapalana, \\ Kamburupitiya 81100, Sri Lanka
}

\begin{abstract}
Discovering new genetic resources for desirable morphological characteristics from traditional rice gene pool is essential as there is a limited variation in the existing improved rice cultivars. The present study was carried out to evaluate the morphological diversity of sixteen randomly selected traditional rice accessions. Their morphological characteristics were evaluated at greenhouse conditions at Faculty of Agriculture, University of Ruhuna in Yala season, 2016. The greenhouse experiment was carried out according to the randomized complete block design with four replicates. Observations were collected on 8 morphological traits and data were analyzed by factor analysis and cluster analysis using SPSS. Rice accessions were classified according to, Standard Evaluation System of International rice research institute (IRRI) and it was found that sixteen rice accessions were categorized into three different groups according to the plant height (tall, intermediate and semi-dwarf) and two different groups according to the tillering ability (very low tillering, low tillering). According to principle component analysis followed by the Ward linkage analysis and hierarchal dendrogram, evaluated rice accessions were classified into four distinct clusters at rescaled cluster distance 7.5. The tested rice accessions have been dispersed in all the four quadrants of in two-dimensional scatter plot diagram. This reveals the great diversity exists within the Sri Lankan traditional rice accessions even in a random sample. The findings of the present study can be utilized for the further research purposes or breeding programs in rice improvement.
\end{abstract}

Keywords: Greenhouse experiment, Morphological characteristics, Sri Lanka, Traditional rice

\section{INTRODUCTION}

Rice is an important cereal crop that provides food for more than half of the world population (Sasaki and Burr, 2000). Morphological evaluation is a preliminary step to estimate the variability and association among cultivars though several other tools are also used broadly (Smith et al., 1991). That's why the establishment of a successful crop improvement programme is very much vital to find out the morphological variability of existing cultivars within the country.

In the low-lying rain-fed areas of tropical Asia, paddy fields are unavoidably subjected to un-

*Corresponding author: bhagyaprabhashini91@gmail.com predictable water depths. Grain yield decreases with increasing water level. Under such circumstances, intermediate height (110-130 $\mathrm{cm})$ is considered as desirable over dwarf height $(90-110 \mathrm{~cm})$. But taller plants are more susceptible to lodging and less responsive to Nitrogen. Intermediate and tall varieties tend to lodge at a close spacing while short and lodging resistant varieties give the highest yield at close spacing (Yoshida, 1981). However, the morphological character that has given high yield is a short, stiff culm that gives lodging resistance (Shigemura, 1966; Chandler, 1968). Changes in morphological characters of rice varieties that are available commercially, indicate that varieties have been chosen for shorter plant height, higher tillering 
ability, and more erect leaves.

Rice is the staple food of Sri Lanka and it is cultivated mostly as a wetland crop in almost all districts. The total land allocated for paddy is estimated to be nearly 792,000 hectares (Central bank, 2018). Sri Lankan agricultural sector contributes to the GDP by $6.9 \%$ and major contribution for the GDP comes from the paddy sector. More than 1.8 million farmer families in Sri Lanka depend on paddy cultivation (Central Bank, 2014). They had produced 2383 metrictons of rice in 2017.

Reintroduction and improvement of traditional rice varieties chosen through mass selection have been reported in various countries (Almekinders and Elings, 2001; Gyawali et al., 2007). The rice germplasm is a rich pool of constructive genes that rice breeders can harness for rice improvement programmes. Genetic variability exists among germplasm leaving a broad capacity for crop improvements. Information on the genetic diversity within and among closely related crop varieties is crucial for a rational use of genetic resources. It helps to screen germplasm and can also be used to forecast potential genetic gains (Singh et al., 2015).

Ikeda and Vaughan (1991) have reported that $O$. sativa varieties which have been cultivated in Sri Lanka from ancient time to 1960s' are known as traditional rice varieties. Sri Lanka has been considered as one of the secondary diversity centers for rice genetic resources. Pri- yangani et al. (2008) has reported that Sri Lanka possesses about two thousands of traditional rice cultivars. These cultivars have distinct morphological characters differ from each other as well as different from modern rice cultivars (Priyangani et al., 2008; Amarasinghe et al., 2012; Ranawake et al., 2014a; Ranawake et al., 2014b).

Even though new improved varieties produce comparatively higher yields, consumer preference is higher for traditional rice varieties owed to their medicinal properties. Additionally, traditional rice varieties are famous due to its high fibre content (Wickramasinghe and Noda, 2008). International Rice Research Institute (IRRI), Philippines identified Sri Lanka as one of the main geographical origins of many valuable traits in rice (IRRI, 2009).

\section{MATERIALS AND METHODS}

Some Sri Lankan traditional rice accessions collected from Plant Genetic Resources Centre, Gannoruwa (PGRC), Sri Lanka were used for the study (Table 1). The experiment was carried out in greenhouse conditions during 2016 Yala season. Dormancy broken, surface sterilized rice seeds were germinated and maintained in nursery beds. Ten days old seedlings were transplanted in pots $(40 \mathrm{~cm} * 30 \mathrm{~cm})$ under greenhouse conditions at the Faculty of Agriculture, University of Ruhuna, Mapalana, Sri Lanka. The experiment was carried out according to Randomized complete block design (RCBD) with three replicates (4 pots per replicate) and three plants for each pot (spacing 15

Table 1: Traditional rice accessions used for the study.

\begin{tabular}{llll}
\hline PGRC* accession number & Accession name & PGRC accession Number & Accession name \\
\hline 3472 & Hatada Wee & 4171 & Rathal \\
3493 & Hondarawala & 4402 & Haththe pas Dawase Wee \\
3573 & Pokkali & 4576 & Pokuru Samba \\
3652 & BurumaThawalu & 4724 & Goda El Wee \\
3724 & GodaHeenati & 4945 & Mada El \\
3735 & WelHandiran & 5488 & Kalukanda \\
4087 & KaluHeenati & 5522 & Mada El \\
4162 & Pokuru Wee & 8499 & Hondarawala \\
\hline
\end{tabular}

*PGRC $=$ Plant Genetic Resource Center, Gannoruwa, Peradeniya, Sri Lanka 
$\mathrm{cm} * 15 \mathrm{~cm})$. The basal dressing was applied before planting and the top dressing was applied $($ Basal dressing $=$ Urea $50 \mathrm{Kg} / \mathrm{ha}$, TSP $62.5 \mathrm{Kg} / \mathrm{ha}$, MOP $50 \mathrm{Kg} / \mathrm{ha}$; Top Dressing $=$ Urea $37.5 \mathrm{Kg} / \mathrm{ha}$ ) two times at two weeks after planting and eight weeks after planting. Data were collected on, plant height $(\mathrm{cm})$, number of tillers per plant, days to $50 \%$ flowering, number of fertile tillers per plant, 100grain weight $(\mathrm{g})$, seed length $(\mathrm{mm})$, seed width ( $\mathrm{mm})$, days to maturity, yield per plant and panicle length $(\mathrm{cm})$.

Data were collected according to the Standard Evaluation System (SES) for rice (IRRI,

2013) which describes as follows;

1. Days to flowering- From the date of seeding to $80 \%$ heading date

2. Plant height $(\mathrm{cm})-$ Actual measurement from soil surface to tip of the tallest panicle, excluding awns

3. Number of total tillers/plant- Tillers at the maturity stage

4. Number of fertile tillers/plant- Number of panicle bearing tillers/plant

5. Panicle length $(\mathrm{cm})$ - from panicle base to tip

6. 100 grain weight(g)- Hundred grains counted from 10 plants of each replicates

7. Seed length $(\mathrm{mm})$ - longitudinal dimension measured from 10 well-developed grains as the distance from the base of the lowermost sterile lemma to the tip (apiculus) of the lemma or pales, whichever is longer. In the case of awned varieties, length is measured to a point comparable to the tip of the apiculum

8. Seed width $(\mathrm{mm})-$ dorsi-ventral diameter measured from 10 grains as the distance across the lemma and the palea at the widest point

9. Days to maturity - The date on which $80 \%$ of the grains on the panicles are fully ripened.

Sri Lankan traditional rice accessions were grouped according to Standard Evaluation System (IRRI, 2013). Rice plants were classified as semi-dwarf (lowland: less than 110 cm; upland: less than $90 \mathrm{~cm}$ ), intermediate (lowland: $110-130 \mathrm{~cm}$; upland $(90-125 \mathrm{~cm})$ and tall (lowland: more than $130 \mathrm{~cm}$; upland: more than $125 \mathrm{~cm}$ ) accessions according to the height. Tillering ability was determined as very high (more than 25 tillers/plant), good (20/25 tillers/plant), medium (10-19 tillers/ plant), low (5-9 tillers/plant) and very low (less than 5 tillers/plant). Traditional rice accessions were grouped by considering days to flowering (Sri Lankan classification) as short duration (105-124 days), medium duration (125-140 days) and late duration (141- 160 days).

Data were subjected to statistical analysis using IBM SPSS 20 statistical software (SPSS Inc, 2011). Morphological diversity among selected traditional rice accessions was identified using principle component analysis (PCA). It was used to determine the optimum number of clusters (Thompson et al., 2003). Ward linkage dendrogram was constructed using cluster analysis in order to obtain morphological relationship among traditional rice accessions (Zapico et al., 2010). The standardized mean values of each morphological characteristic were statistically analyzed using SAS. PCA, cluster analysis and Ward linkage dendrogram were used to study the patterns of the morphological diversity in traditional rice cultivar as described by Mooi and Sarstedt (2011).

\section{RESULTS AND DISCUSSION Grouping traditional rice accessions ac- cording to standard evaluation system}

International rice research institute has developed guidelines to categorize rice cultivars into diverse groups (IRRI, 2013). The developed standard evaluation system (SES) helps to rice researchers all over the world to separate rice cultivars into standard define groups. Several numbers of parameters such as plant height, the number of total tillers per plant, the number of fertile tillers per plant, days to flowering, filled grain percentage is considered to be group rice accessions in SES. 


\section{Grouping of traditional rice accessions ac- cording to plant height}

According to the SES of IRRI (IRRI, 2013), selected traditional rice accessions were categorized as semi-dwarf, intermediate and tall as given in Table 2. Out of 16 rice accessions, 14 rice accessions were semi-dwarf $(<110$ $\mathrm{cm}), 1$ rice accession was intermediate (110$130 \mathrm{~cm})$ and 1 rice accession was tall $(>130$ $\mathrm{cm})$.

Significantly highest plant height was recorded in Wel Handiran-3735 and had an mean value of $131.2 \mathrm{~cm}$. The shortest rice accession Rathal-4171, recorded $80.4 \mathrm{~cm}$ for plant height (Table 2). Plant height is a major attribute which contributes to the grain yield of rice (Yadav et al., 2011). But increased plant height prone to lodging and reduce the grain yield, quality of production and mechanical harvesting efficiency in rice (Weber and Fehr, 1966; Kono, 1995).

\section{Grouping traditional rice accessions ac- cording to tillering ability}

Considering the tillering ability, traditional rice accessions were grouped according to the IRRI, SES as given in Table 3. About $62.5 \%$ of the tested traditional rice accessions pro- duced 5-9 tillers per plant. Significantly higher number of tillers were recorded by the traditional rice accessions Kalu Heenati-4087, Pokuru wee-4162 and Haththe Pas Dawase Weewhich were around 9 tillers per plant on average (Table 3). About 37.5\% evaluated traditional rice accessions recorded less than 5 tillers per plant which showed very low tillering ability. The lowest number of tillers per plant was recorded in Hondarawala-3493, Mada El-5522 and Rathal had a value of 3 tillers per plant. None of the traditional rice accession belonged to medium (10-19 tillers/ plant), good (20-25 tillers/plant) or very high (more than 25 tillers/plant) tillering categories.

Development of inbred rice cultivars with new plant architecture has been already identified as one of the opportunities in future rice improvement programmes (Rajapakse et al., 2000). For that reason, the identification of morphological characteristics such as plant height, number of tillers and number of fertile tillers are vital to change the plant architecture of rice. Therefore, the results obtained from the present study with other morphological data can be broadly applicable for crop improvement in future.

Table 2: Grouping traditional rice accessions according to plant height using IRRI, SES (IRRI, 2013)

\begin{tabular}{llll}
\hline Plant type & PGRC accession number & Accession name & Mean plant height (cm) \\
\hline Semi- dwarf $(<110 \mathrm{~cm})$ & 3472 & Hatada Wee & $106.1^{\mathrm{bc}}$ \\
& 3573 & Pokkali & $99.1^{\mathrm{bcd}}$ \\
& 3652 & Buruma Thawalu & $99.6^{\mathrm{bcd}}$ \\
& 3724 & Goda Heenati & $102.1^{\mathrm{bc}}$ \\
& 4087 & Kalu Heenati & $103.5^{\mathrm{bc}}$ \\
& 4162 & Pokuru Wee & $92^{\mathrm{ecd}}$ \\
& 4171 & Rathal & $80.4^{\mathrm{e}}$ \\
& 4402 & Haththe Pas Dawase Wee & $101.9^{\mathrm{bc}}$ \\
& 4576 & Pokuru Samba & $83.1^{\mathrm{ed}}$ \\
& 4724 & Goda El Wee & $81.6^{\mathrm{e}}$ \\
& 4945 & Mada El & $79.8^{\mathrm{e}}$ \\
& 5488 & Kalukanda & $102^{\mathrm{bc}}$ \\
\hline Intermediate $(110-130 \mathrm{~cm})$ & 3493 & Mada El & $78.5^{\mathrm{e}}$ \\
\hline Tall $(>130 \mathrm{~cm})$ & Hondarawala & $102.8^{\mathrm{bc}}$ \\
\hline
\end{tabular}

DMRT groups of each treatment are indicated in superscripts. Means with the same letters are not significantly different $(\mathrm{P}<0.05)$. 
Grouping of traditional rice accessions according to days to flowering

According to the Sri Lankan classification for days to flowering (Personal communication, Department of Agriculture), tested traditional rice accessions were grouped as shown in Table 4 .

About $19 \%$ of tested rice accessions completed $50 \%$ flowering within $<50$ days while
$37.5 \%$ of rice accessions took 75-99 days for the same. About $44 \%$ of rice accessions completed $50 \%$ flowering within a period of 100 124 days. The shortest days to flowering (44 days) was recorded by Mada El-5522. Pokuru Wee-4162 recorded the significantly highest days to flowering with 113 days (Table 4 and $5)$.

All the other recorded morphological charac-

Table 3: Grouping of traditional rice accessions according to number of total tillers per plant using IRRI, SES (IRRI, 2013)

\begin{tabular}{lclc}
\hline Tillering ability & PGRC accession number & Accession name & Mean number of total tillers/plant \\
\hline Very low & 3493 & Hondarawala & $3^{\mathrm{e}}$ \\
tillering & 4171 & Rathal & $3^{\mathrm{e}}$ \\
(<5 tillers/plant) & 4724 & Goda El Wee & $4^{\text {ed }}$ \\
& 4945 & Mada El & $4^{\text {ed }}$ \\
& 5488 & Kalukanda & $4^{\text {ed }}$ \\
\hline Low tillering & 5522 & Mada El & $3^{\text {e }}$ \\
(5-9 tillers/plant) & 3472 & Hatada Wee & $5^{\text {cde }}$ \\
& 3573 & Pokkali & $7^{\text {bcd }}$ \\
& 3652 & BurumaThawalu & $7^{\text {bd }}$ \\
& 3724 & GodaHeenati & $6^{\text {bcd }}$ \\
& 3735 & WelHandiran & $8^{\text {ab }}$ \\
& 4087 & KaluHeenati & $9^{\text {a }}$ \\
& 4162 & Pokuru Wee & $9^{\text {a }}$ \\
& 4402 & Haththe Pas Dawase Wee & $9^{\text {a }}$ \\
& 4576 & Pokuru Samba & $6^{\text {bd }}$ \\
\hline
\end{tabular}

DMRT groups of each treatment are indicated in superscripts. Means with the same letters are not significantly different $(\mathrm{P}<0.05)$.

Table 4: Grouping traditional rice accessions according to days to flowering using Sri Lankan classification (Department of Agriculture, Sri Lanka)

\begin{tabular}{|c|c|c|c|}
\hline Classification & PGRC accession number & Accession name & Days to flowering \\
\hline$<$ 50days & $\begin{array}{l}5522 \\
4945 \\
5488\end{array}$ & $\begin{array}{l}\text { Mada El } \\
\text { Mada El } \\
\text { Kalukanda }\end{array}$ & $\begin{array}{l}44^{\mathrm{g}} \\
45^{\mathrm{g}} \\
49^{\mathrm{g}}\end{array}$ \\
\hline $75-99$ days & $\begin{array}{l}4402 \\
3735 \\
4087 \\
4724 \\
4576 \\
3573 \\
4171\end{array}$ & $\begin{array}{l}\text { Haththe Pas Dawase Wee } \\
\text { Wel Handiran } \\
\text { Kalu Heenati } \\
\text { Goda El Wee } \\
\text { Pokuru Samba } \\
\text { Pokkali } \\
\text { Rathal }\end{array}$ & $\begin{array}{l}72^{\mathrm{f}} \\
80^{\mathrm{de}} \\
81^{\mathrm{de}} \\
82^{\mathrm{de}} \\
84^{\mathrm{de}} \\
91^{\mathrm{c}} \\
93^{\mathrm{c}}\end{array}$ \\
\hline 100-124 days & $\begin{array}{l}3652 \\
3472 \\
34938499 \\
3724 \\
4162\end{array}$ & $\begin{array}{l}\text { Buruma Thawalu } \\
\text { Hatada Wee } \\
\text { Hondarawala } \\
\text { Hondarawala } \\
\text { Goda Heenati } \\
\text { Pokuru Wee } \\
\end{array}$ & $\begin{array}{c}100^{\mathrm{c}} \\
104^{\mathrm{b}} 105^{\mathrm{b}} \\
106^{\mathrm{b}} \\
77^{\mathrm{ef}} \\
113^{\mathrm{a}}\end{array}$ \\
\hline
\end{tabular}

DMRT groups of each treatment are indicated in superscripts. Means with the same letters are not significantly different $(\mathrm{P}<0.05)$. 
teristics are shown in Table 5.

Construction of Ward linkage dendrogram using Principle Component Analysis (PCA), factor analysis and cluster analysis to demonstrate the diversity of traditional rice accessions

The PCA was carried out for the analysis of morphological characteristics of 16 traditional rice accessions (Table 5). Eigenvalue, percentage of variance and cumulative Eigenvalues of morphological characteristics of evaluated traditional rice accessions are shown in Table 6.

Among 9 principle components, two principle components (PCs) described more than one Eigenvalue and explained about $73.33 \%$ cumulative variability of the morphological characteristics. These two PCs 1 and 2 described variability of $41.2 \%$ and $32.03 \%$, respectively. Based on the rotated component matrix, the evaluated morphological characteristics were grouped according to their designated components (Table 7). Among the tested morphological characteristics, days to flowering, plant height, number of total tillers, number of fertile tillers and days to maturity were described by PC 1 while, hundred grain weight, grain width and grain length were described by PC 2 .

The output of PCA was described by cluster analysis using Ward's linkage. All the tested traditional rice accessions were clustered into four morphologically distinct clusters at the rescaled cluster distance of 7.5 (Figure 1, Table 8). At the rescaled cluster distance of 25 , two distinct clusters were resulted due to the wide diversity among evaluated traditional rice accessions.

The morphologically similar traditional rice accessions were included into the same clusters by considering the agronomic characteristics. Morphological traits can be used successfully to characterization of rice accessions (Tehrim et al., 2012). Results of the present

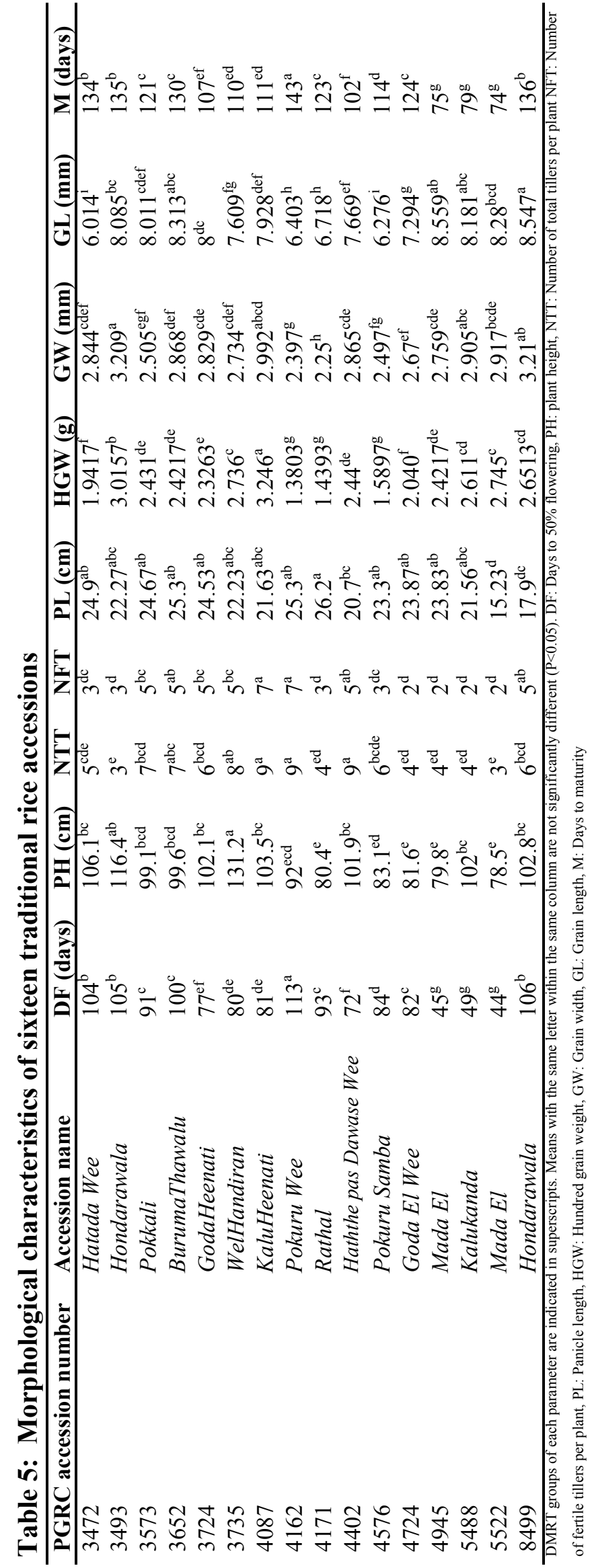


study revealed that all the evaluated traditional rice accessions possess a considerable range of morphological variation.

According to Ali et al. (2000), cluster analysis has a remarkable effectiveness and capability to identify accessions with the highest level of similarity. Suriyagoda et al. (2011) have also revealed a wide variability of rice accessions using cluster analysis. The dendro-

Table 6: Eigen value, percentage of variance and cumulative Eigenvalues of morphological characteristics of evaluated traditional rice accessions

\begin{tabular}{llll}
\hline $\begin{array}{l}\text { Principle } \\
\text { component }\end{array}$ & Eigenvalue & $\begin{array}{l}\% \text { of } \\
\text { variance }\end{array}$ & $\begin{array}{l}\text { Cumulative } \\
\%\end{array}$ \\
\hline 1 & 3.716 & 41.289 & 41.289 \\
2 & 2.884 & 32.039 & 73.328 \\
3 & 0.983 & 10.921 & 84.250 \\
4 & 0.619 & 6.881 & 91.131 \\
5 & 0.497 & 5.527 & 96.658 \\
6 & 0.156 & 1.731 & 98.389 \\
7 & 0.087 & 0.968 & 99.357 \\
8 & 0.055 & 0.609 & 99.966 \\
9 & 0.003 & 0.034 & 100.000 \\
\hline
\end{tabular}

Table 7: Rotated component matrix ${ }^{a}$ extracted from PCA

\begin{tabular}{lcc}
\hline \multicolumn{3}{c}{ Component } \\
\hline Variables & 1 & 2 \\
\hline DF & $\mathbf{. 8 4 9}$ & -.291 \\
PH & $\mathbf{6 3 1}$ & .473 \\
NTT & $\mathbf{7 8 6}$ & -.034 \\
NFT & $\mathbf{. 8 7 3}$ & .057 \\
PL & .276 & $\mathbf{- . 7 0 9}$ \\
HGW & .034 & $\mathbf{. 9 5 9}$ \\
GW & .076 & $\mathbf{. 8 8 0}$ \\
GL & -.174 & $\mathbf{. 8 1 5}$ \\
M & $\mathbf{. 8 5 3}$ & -.294 \\
\hline Rotation Method: Varimax with Kaiser Normalization. \\
a. Rotation converged in 3 iterations.
\end{tabular}

gram acquired from the present study also provide evidence for that in terms of similarity existing among traditional rice accessions. However, Singh and Rachie (1985) have reported that the genetic make-up of seed, environment and field management practices also influence the morphology of a crop.

Cluster 1 and cluster 4 contain five each traditional rice accessions while cluster 2 and 3 comprise three each rice accession (Table 8). Cluster 1 contains semi-dwarf rice accessions except for WelHandiran-3735 and all accessions were low tillering which produced 6-9 tillers per plant. Among clustered rice accessions, $60 \%$ of the accessions took 100-102 days for $50 \%$ flowering.

Cluster 2 contains three rice accessions and both Hodarawala accessions are semi-dwarf and Hondarawala-8499 and Hondarawala3493 clustered together in cluster 2 and both started flowering between 100-124 days. Most probably these two accessions would be duplicated. A proper genetic study should be carried out to confirm it. Mada El-4945 and Mada El-5522 which have the same accession name were included into cluster 3 . Cluster 3 rice accessions were early flowering, (50-74 days) and classified as semi-dwarf. All the tested rice accessions clustered in cluster 4 were semi-dwarf and $60 \%$ of rice accessions took 75-99 days to $50 \%$ flowering. Hatada Wee-3472 and Pokuru Wee-4162 took 100124 days to $50 \%$ flowering.

The two-dimensional scatter plot diagram (Figure 3) consisted of four quadrants illustrates the distribution of 16 traditional rice accessions according to the diversity of their

Table 8: Clustering of traditional rice accessions

\begin{tabular}{ll}
\hline $\begin{array}{l}\text { Cluster } \\
\text { number }\end{array}$ & Traditional rice accessions \\
\hline Cluster 1 & $\begin{array}{l}\text { Buruma Thawalu-3652, Goda Heenati-3724, Pokkali-3572,Wel Handiran-3735,Haththe Pas Dawase } \\
\text { Wee-4402 }\end{array}$ \\
Cluster 2 & Kalu Heenati-4087, Hondarawala-8499, Hondarawala-3493 \\
Cluster 3 & Mada El-4945, Kalukanda-488, Mada El-5522 \\
Cluster 4 & Rathal-4171,Pokuru Samba-4576,Goda El Wee-4724,Hatada Wee-3472,Pokuru Wee-4162 \\
\hline
\end{tabular}


morphological characteristics. The traditional rice accessions belonged to cluster 1 (except Pokkali-3573) and cluster 2 have been included into the first quadrant of the 2D scatter plot diagram. Pokkali-3573 from cluster 1 and Hatada Wee-3472, Pokuru Wee-4162 which are from cluster 4 have been included into the second quadrant. The third quadrant consisted

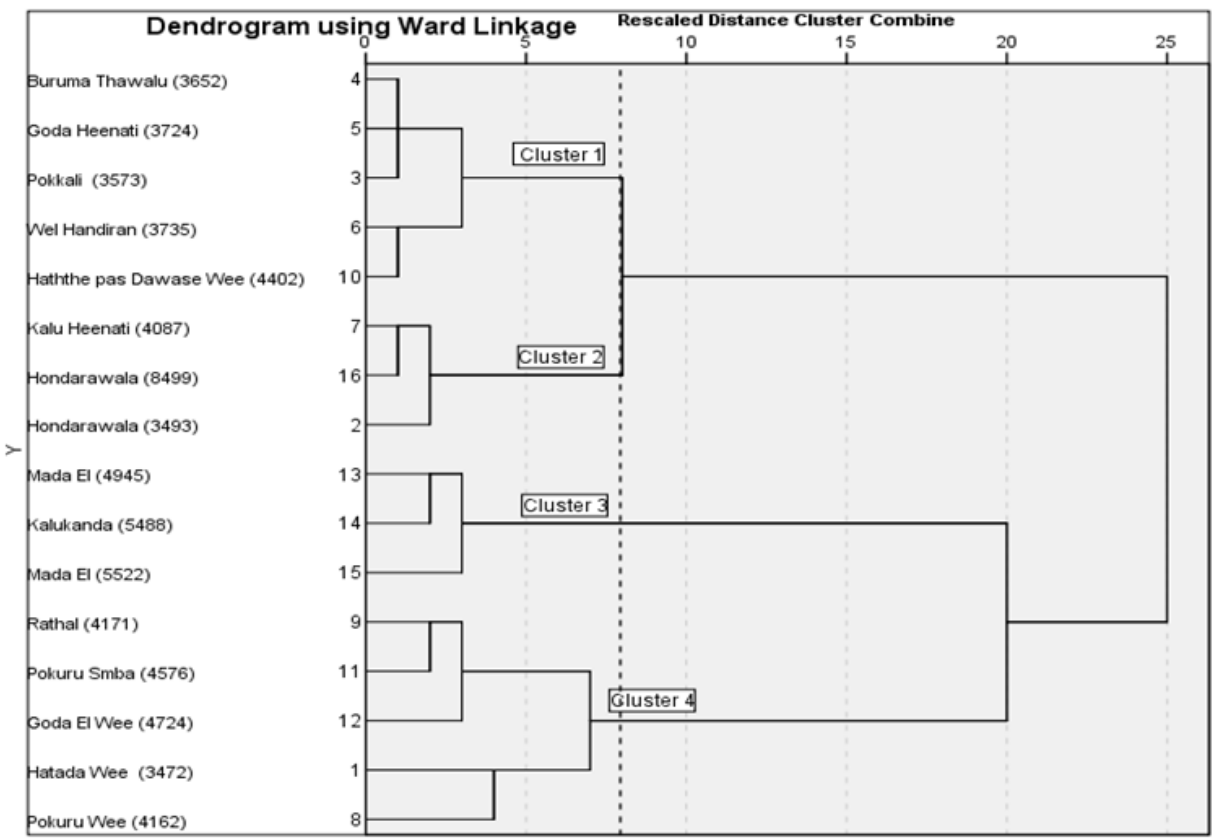

Figure 1: Cluster analysis showing the diversity among traditional rice accessions based on nine morphological characteristics. Dashed line indicates the rescaled distance where clusters were identified.

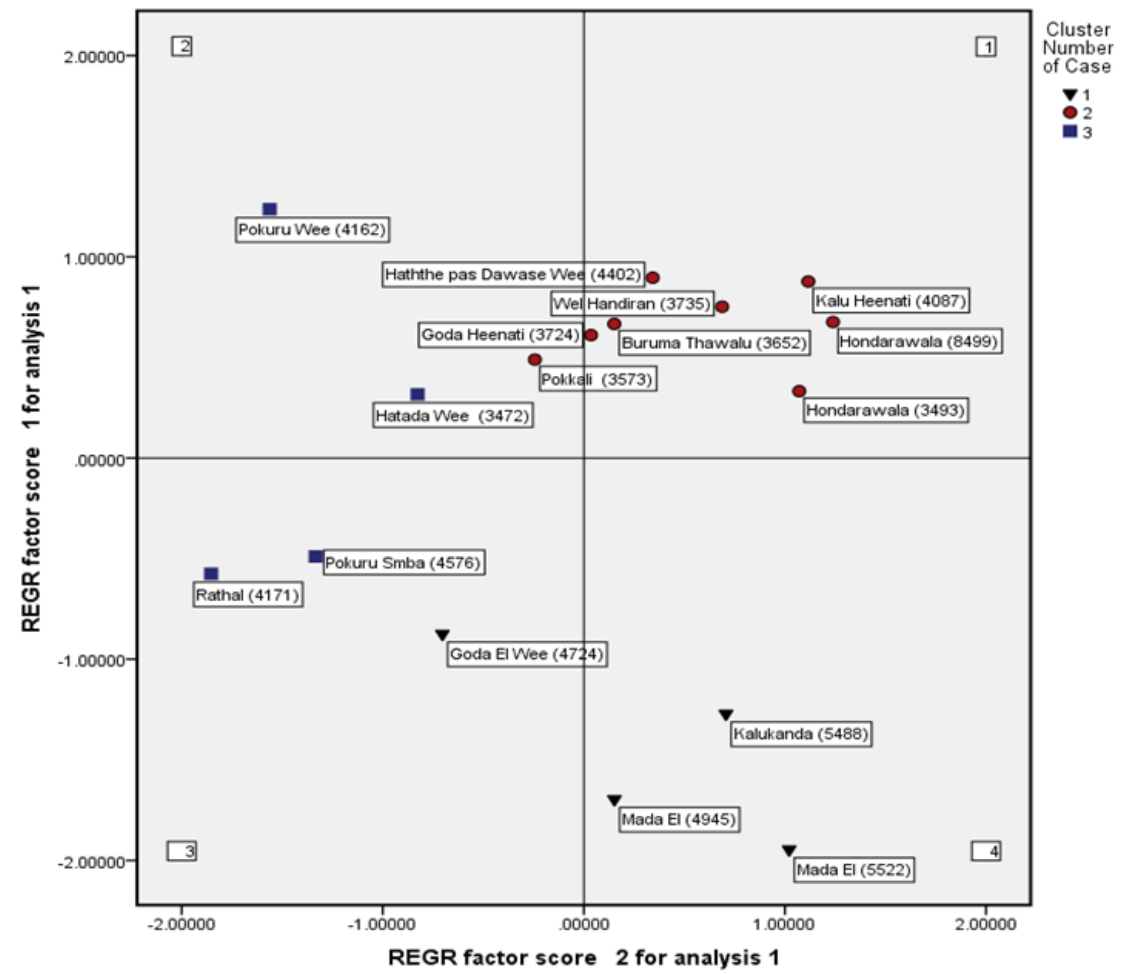

Figure 2: Two-dimensional (2D) scatter plot diagram representing the clusters of traditional rice accessions. 1, 2, 3 and 4 represent the first, second, third and fourth quadrants respectively. 
of Rathal-4171, Pokuru Samba-4576 and Goda El Wee-4724 which belonged to cluster 4 . The all traditional rice accessions belonged to cluster 3, namely Mada El-4945, Mada El5522 and Kalukanda-5488 have been included into the fourth quadrant (Figure 2, Table 8 ). Since 16 traditional rice accessions have been shown a good distribution among all the four quadrants, the diversity of tested traditional rice accessions is wide.

Although diversity of traditional rice accessions can be studied in this method, Li et al. (2006) has highlighted that because of environment consequences, phenotypic values may not be an ideal method for grouping rice accessions. Much improved genetic studies and molecular markers should be used for an accurate diversity analysis.

\section{CONCLUSION}

Considerable range of morphological variation has been found in evaluated traditional rice accessions. Rice accessions were included into three different groups according to plant height (tall, intermediate and semidwarf), two different groups according to tillering ability (very low tillering, low tillering) and three groups according to days to $50 \%$ flowering. According to the Ward linkage dendrogram, evaluated rice accessions were belonged to four distinct clusters at rescaled cluster distance 7.5 and described two principle components. In two-dimensional scatter plot diagram, tested rice accessions have been dispersed in all quadrants. PGRC contained some accessions which showed duplications and need to confirm it through proper molecular techniques. The study can be utilized for rice improvement programs.

\section{ACKNOWLEDGEMENT}

Authors would like to acknowledge PGRC, Gannoruwa, Peradeniya, Sri Lanka for providing seeds of Sri Lankan traditional rice accessions.

\section{REFERENCES}

Ali SS, Jafri SJH, Mahmood A and Butt MA 2000 Heritability of yield and yield components of rice. Pakistan Journal of Agricultural Research 16(2): 89-91.

Almekinders CJM and Elings A 2001 Collaboration of farmers and breeders: Participatory crop improvement in perspective. Euphytica 122(3): 425-438. and yield components. Crop Science, 33(2): 249-252.

Amarasinghe UGS, Ranawake AL, Dahanayake $\mathrm{N}$ and Wanithunge U $2012 \mathrm{Ag}$ ronomic characters of some traditional rice cultivars in Sri Lanka, $9^{\text {th }}$ Academic sessions, university of Ruhuna: 82.

Central Bank 2014 Economic and Social Statistics of Sri Lanka 2014- Volume.

Central Bank 2017 Annual Report, Central Bank of Sri Lanka, Colombo.

Chandler RF JR. 1968 Dwarf rice - a giant in Asia. In United States Department of Agriculture. Year book of agriculture. 1968. Science for better living.

Gyawali S, Sunwar S, Subedi M, Tripathi M, Joshi KD and Witcombe JR 2007 Collaborative breeding with farmers can be effective. Field Crops Research 101 (1): 88-95.

Ikeda R and Vaughan DA 1991 The distribution of resistance genes to the brown planthopper in rice germplasm. RGN 8: 1-3.

IRRI Annual Report 2009, Retrieved on $15^{\text {th }}$ August $2016 \quad \mathrm{http} / /$ www.knowledgebank.IRRI

IRRI, 2013 Standard evaluation system for rice. The International rice testing program. $5^{\text {th }}$ Edition, The International Rice Research Institute, Los Banos, Philippines.

Li C, Zhou A and Sang T 2006 Genetic analysis of rice domestication syndrome with the wild annual species, Oryza nivara. New phytologist, 170 (1): 185194.

Mooi E and Sarstedt M 2011 A Concise 
Guide to Market Research: The Process, Data, and Methods Using IBM SPSS Statistics, Heidelberg, Springer.

Priyangani EGD, Kottearachchi NS, Attanayaka DPSTG and Pathinayake BD 2008 Characterization of Suwandal and Heenati rice varieties for the fragrance gene using Polymerase Chain Reaction based molecular markers. Doctor of Philosophy, Faculty of Agriculture and plantation management, Wayamba University of Sri Lanka.

Rajapakse RMT, Sandanayake CA and Pathinayake BD 2000 Foot prints in rice variety improvement and its impact on rice production in Sri Lanka. In Annual Symposium of the Department of Agriculture, Sri Lanka (Vol. 2, p. 42).

Ranawake AL, Amarasinghe UGS and Senanayake SGJN 2014a Submergence tolerance of some modern rice cultivars at seedling and vegetative stages. Journal of Crop and Weed, 10(2): 240-247.

Ranawake AL and Hewage MJ 2014b Correlation analysis of drought, salinity and submergence tolerance in some traditional rice cultivars of Sri Lanka. International Journal of Scientific and Research Publications: 54.

Sasaki T and Burr B 2000 International Rice Genome Sequencing Project: the effort to completely sequence the rice genome. Current opinion in plant biology 3(2): 138-142

Shigemura S 1966 Contribution of newly developed varieties to increased production of rice in the warm district of Japan: a case study of Hoyoku etc. JARQ 1:1-6

Singh A, Saini R, Singh J, Arya M, Ram M and Singh PK 2015 Genetic diversity studies in rice (Oryza sativa L.) using microsatellite markers. International Journal of Agriculture, Environment \& Biotechnology 8(1): 143.

Singh SR and Rachie KO (Eds.). 1985 Cowpea Research, Production and Utilisation . Pp 74-75 John Wiley and Sons
Ltd., Chichester.

Smith SE, Al-Doss A and Warburton M 1991 Morphological and agronomic variation in North African and Arabian alfalfas. Crop Science, 31(5): 11591163.

SPSS I.I.B.M 2011 IBM SPSS Statistics for Windows, Version 20.0. Armonk, NY: IBM Corp.

Suriyagoda LDB, Thilakarathne RMMS, Nissanka SP and Samita S 2011 Morphological variation in selected rice (Oryza sativa L.) germplasm of Sri Lanka. Journal of the National Science Foundation of Sri Lanka 39(2).

Tehrim S, Pervaiz ZH, Mirza MY, Rabbani MA and Masood MS 2012 Assessment of phenotypic variability in rice (Oryza sativa L.) cultivars using multivariate analysis. Pakistan Journal of Botany 44(3): 999-1006.

Thomson MJ, Tai TH, McClung AM, Lai XH, Hinga ME, Lobos KB, Xu Y, Martinez CP and McCouch SR 2003 Mapping quantitative trait loci for yield, yield components and morphological traits in an advanced backcross population between Oryza rufipogon and the Oryza sativa cultivar Jefferson. Theoretical and Applied Genetics, 107(3), pp. 479-493.

Wickramasinghe HAM and Noda T 2008 Physicochemical properties of starches from Sri Lankan rice varieties. Food science and technology research 14(1): 49-54.

Yoshida S 1981 Fundamentals of Rice Crop Science. IRRI, Los Banos, the Philippines. 269p.

Zapico FC, Namocatcat JA and Cariño-Turner JL 2010 Genetic diversity analysis of traditional upland rice cultivars in Kihan, Malapatan, Sarangani Province, Philippines using morphometric markers. Philippine Journal of Science, 139 (2): 177-180. 